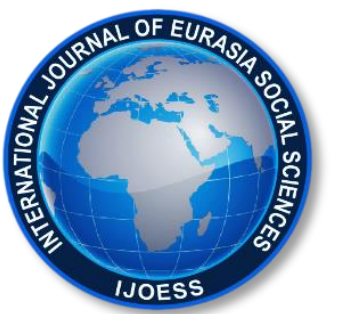

International Journal of Eurasia Social Sciences

Vol: 11, Issue: 39, pp. (1-10).

Article Type: Research Article

Received: 25.03.2019 Accepted: 20.03.2020

\title{
SELF-DIRECTED LEARNING: INVESTIGATING LEARNER BELIEFS
}

\author{
Betul TARHAN
}

Dr., Bahcesehir University, Turkey, tarhan@uga.edu

\begin{abstract}
Research in the area of self-directed learning has primarily focused on finding out the characteristics of self-directed learners by observing them. However, less attention is given to the perspectives and beliefs of self-directed learners. This tudy aims to present what self-directed learners think and say about self-directed learning to find out what is required or necesary to be a self-directed learner. Individual semi-structured interviews were conducted. This study is designed as a qualitative study. Charmaz's constructivist grounded theory is employed. Indepth interviews are done to understand the beliefs and perspectives of self-directed learners. The interviews are recorded, transcribed, and analyzed using qualitative research method for themes surrounding self-directed learning. Three major themes emerged from the data: (a) definition of self-directed learning, (b) external and internal resources and (c) suggestions that could be made for parents, teachers and communities to raise self-directed individuals. The proposed model presents a comprehensive understanding of self-directed learning. The model can be adopted by institutions and can be expanded with further studies by future researchers. The each component of this model could be studied by researchers to find out more about the internal and external resources and the suggestions that could be provided for the community.
\end{abstract}

Keywords: Self-directed learning, adult education, education policy, qualitative research. 


\section{INTRODUCTION}

Self-directed learning has attracted the attention of scholars as a psychological dimension since 1970s. Brockett and Hiemstra (1991) emphasize that self-directed learning is not some mere temporary enthusiasm but a way of life for the learner. Given the appropriate environment, material and conditions, a learner-individual can learn and continue to learn throughout life with self directed learning (Elias \& Merriam, 1980; Sze-Yeng \& Hussain, 2010). Such a frequent use of the notion of "individual" implies an influence of humanism. Indeed, it is apparent that in adult education self-directed learning has sprung out of the roots of humanism. Morris (2019) also states that self-directed learning holds a place in humanistic philosophy and constructivist epistemology. Giving importance to the implications of self-directed learning displays respect for the human.

Self-directed learning is described, in adult education, as an instructional process where a learner assumes primary responsibility for the learning process, and as a personality characteristic centering on a learner's desire or preference for assuming responsibility for learning (Brockett, 1983). However, self-directed learning is not a single concept which can be identified in a well-formulated definition. It is, rather, a coherent set of features characterizing a certain group of learners. Although there are numerous definitions of self-directed learning, it is generally defined as a capacity of learners to learn on their own (Kowles, 1970; Guglielmino, 1978; Sze-Yeng \& Hussain; 2010; Brookfield, 2013). Among a variety of definitions and descriptions as to what selfdirected learning is, Knowles' widely known and accepted description includes the following points:

1) Self-directed learning is a process;

2) Individuals take the initiative to make a choice between being with other people or standing alone;

3) They diagnose own learning needs;

4) They formulate learning goals;

5) They identify human and material resources for learning, choose and implement appropriate learning strategies, and evaluate learning outcomes (Knowles 1970). Merriam and Caffarella (1999) define selfdirected learning as a process in which learners plan, implement and evaluate their learning experience. In such an experience, individuals take the initiative to make the choice between being with other people or standing alone; and, hence, they set their own learning goals and assess their own learning needs (Knowles, 1975; Brockett and Hiemstra, 1991). Like the definition of Knowles (1975), the scholars like Merriam and Caffarella (1999) state that self-directed learning is a process in which the learner makes the plans for his/her learning. Knowles's (1990) later description of self-directed learning emphasizes the learner's characteristics. He defines the self-directed learners as problem solvers, active learners, and strategic learners.

Self-directed learning is not some pleasant, desirable or temporary enthusiasm but only a basic human capacity in that one's learning on his/her own turns into a predominant condition in the contemporary world (Brockett and Hiemstra 1991, Knowles 1975). Personal responsibility is envisioned as the cornerstone of self-direction in learning (Brockett and Hiemstra 1991). It seems that when the individual assumes the responsibility of learning and develops a positive attitude toward the subject to be learnt, realization of learning becomes possible. Selfdirection in learning corresponds to the endeavors of planning, implementation and evaluation by the learner 
(Brockett \& Hiemstra 1991, Brockett 1983). Knowles (1975) formulated SDL as a straight-line model in which learners follow some phases to achieve their learning goals. Similar to Knowles' (1975) perspective, Brookfield (1986) described as a process in which learners can decide to learn independently or with others and take the responsibility of their learning for planning, implementing, and evaluating their own learning. Interactive and instructional aspects were inserted into these models (Brockett \& Hiemstra, 1991; Garrison, 1997; Grow, 1991). Garrison (1997) was influenced by Knowles and Brookfield work and developed a three-dimension model of self-directed learning: 1) self-management, 2) self-monitoring, 3) motivation. Abd-El Fattah (2010) examined the relationship among motivation, self-monitoring and self-management. He put forth that self-management influences self-control and motivation, and self-motivation also affects self-monitoring. Self-directed learning studies are generally done by students who are taught in traditional classroom settings. However, if we accept it as a capacity, the study needs to be conducted by self-directed learners to find out the other components of the existing models. Therefore, this study aims to develop the existing models and find out the other components which make self-directed learning easier for learners.

\section{METHOD}

The aim of the study was to investigate life-long learners' perceptions and beliefs about self-directed learning. Therefore, this article presents a qualitative interview study that documents the participants' beliefs and suggestions regarding self-directed learning. To investigate self-directedness, this article asks the following questions: (a) How do the participants describe self-directed learning? (b) Do they think that they are selfdirected learners? (c) If they are self-directed learners, how have they developed their strategies for being a self-directed learner? With the help of these research questions, the researcher will present a more comprehensive model.

In this study, I followed Charmaz' (2006) constructivist version of grounded theory. Charmaz (2006) suggested that the researcher should explore the participants' concerns related to the area. Constructivist version of grounded theory has been chosen since it acknowledges subjectivity, researcher's involvement and interpretation of data (Charmaz, 2006). Moreover, "constructivist approach sees both data and analysis as created from shared experiences and relationships with participants and other sources of data" (Charmaz, 2014: 239). The researcher followed the publishing ethics and research ethics.

\section{Participant Selection}

I decided to choose the interviewees from among the people I know quite very well as my friends. I have known them for several years and I have had chances to observe them in different settings. Since interviewing is an elicitation technique as classified by Nunan (1992), it would be more efficient for us to try to elicit information from people who would feel comfortable sharing their stories with us.

For this study, purposeful sampling was used to select participants (Creswell, 1998); and I used the following selection criteria for the research participants: (a) defining themselves as self-directed learners, (b) upon encountering a problem, seeking solutions, (c) preferring not passive but active learning, (d) continuing their 
education incessantly. Purposive sample sizes are often determined on the basis of theoretical saturation (Patton, 1990), so the sample size of this study has provided the researcher with reaching a theoretical saturation. Qualitative study does not aim to generalize the outcome (Patton, 1990; Şimşek \& Yıldırım, 2013). According to Adelman, Jenkins, and Kemmis (1980), the knowledge generated by qualitative research is significant in its own right, so this study does not aim to generalize the research findings which is not expected attribute (Leung, 2015).

\section{Participants' Demographic Information}

Six self-directed learners participated in this study. To protect the identity of the participants, their actual names were replaced with pseudonyms. Their demographic information is given in Table 1.

Table 1. Research Participants' Demographic Information

\begin{tabular}{lllll}
\hline Name & Gender & Age & Education & $\begin{array}{l}\text { Parents' } \\
\text { Education }\end{array}$ \\
\hline Mrs. Sanders & Female & 61 & College student & B.A. \\
\hline Mrs. Clayton & Female & 65 & M.A in Literature & Below tertiary \\
\hline Mrs. Jacob & Female & 55 & B.A. & B.A. \\
\hline Mr. Pounder & Male & 57 & B.A. & B.A \\
\hline Mr. Dean & Male & 60 & Ph.D. & B.A. \\
\hline Mr. Burns & Male & 52 & B.A. & B.A. \\
\hline
\end{tabular}

\section{Data Collection and Analysis}

The researchers conducted one semi-structured interview session for each of the self-directed learners. All interviews were conducted face to face. The interview questions clustered around three major themes: a) definition of self-directed learning, (b) external and internal resources, and (c) suggestions that could be made for parents, teachers and communities to raise self-directed individuals.

The process of developing semi-structured interview guide followed the steps of reviewing the related literature, specifying research questions, and forming the interview guide. The researchers collected the data from the interviews and each participant is interviewed three times during the 2018-2019 fall semester, each lasting about 60-75 minutes. The data were transcribed with the audio recordings frequently rewound and listened to several times to ensure the accuracy of the transcription, and coded with attention to constant comparison between participants by using Glaser and Strauss's (1967) and Strauss's (1987) constant comparative method to define the categories. The researchers examined the dimensions of objectivity, credibility, and internal validity (Miles \& Huberman, 1994).

\section{FINDINGS (RESULTS)}

The aim of the study was to determine what lifelong learners meant about self-directed learning. The researchers focused on drawing out patterns and themes that might help current and future parents or educators who want to raise self-directed learners. The researchers tried to find out the characteristics of the self-directed learners and their suggestions or advice to parents or educators. 


\section{Participants' Definition of Self-directed Learning}

Participants' definition of self-directed learning was quite similar to that found in the relevant literature, in which it is defined as a capacity to learn on one's own (Brockett \& Hiemstra, 1990); however they provide a bigger picture for self-directed learning. Mrs. Sanders, the first interviewee, formulates self-directed learning as: "Self-directed learning means to have the ability to follow a course plan without having a teacher in front of you."

Grow (1991) states that self-directed learners set their own goals and they decide with or without help from others (p. 133), adding that "learners at this stage are both able and willing to take responsibility for their learning, direction, and productivity" (134). Mrs. Clayton, the second interviewee, defines self-directed learning as: "Self-directed learning means that studying on your own by determining your own goals"

It is noteworthy that she emphasizes the importance of planning and implementing the plans being made in line with the descriptions of Brockett and Hiemstra (1991) and Benson (2001) as to the characteristics of selfdirected learners: the learner takes over the basic responsibilities of planning, applying, and organizing. The perspective of Mrs. Clayton regarding planning and implementation coincides, albeit partially, with Brockett and Hiemstra (1991) and Benson (2001). Mrs. Sanders says, "To me, self-directed learning is an ability to take the learning initiation by yourself". Her definition can be aligned with the personal qualities of self-directed learning as studied and defined in Holec (1981). Mr. Burns focuses on the rate of progress in self-directed learning when he says, "studying on your own pace is self-directed learning." Mr. Dean conveys the cognitive side of self-direction, "Self-direction is a continuous process that you do without conscious thought and it is a strategy-based learning." Similarly, Mr. Pounder says, "It is something in your brain and encourages you to learn on your own." Their definitions are important to illustrate that they actually know they are self-directed learners and participants' definitions are aligned with the literature.

\section{Internal and External Resources}

The second theme that emerged from the participants was the internal and external resources, which play a great role in being a self-directed learner. Several times throughout the research data, the participants are found to be referring to self-discipline, motivation, curiosity, and knowing one's own abilities. Mrs. Sanders says:

The first one is self-discipline. The first one-so it's being able to not do the things you want to do when you know you really should do something for your planned project. That kind of selfdiscipline is necessary. But another internal resource is knowing yourself well.

Mrs. Clayton defines it as an internal source: "I would define it as an inner-directed, an inner sense of curiosity, which has passion to it to understand or to know." Her definition of self-directed learning was along similar lines with Bandura (1991), who focused on the motivation and self-regulation components of self-directed 
learning. The participant has the belief that curiosity could be one of the most important constituents of finding the desire to learn on one's own. Mrs. Clayton emphasizes, "They have to talk to themselves."

Regarding external resources, they focus on different things. Mr. Burns says, "I like to have at least one table in the house that is empty space, just a computer and the keyboard and not much else, cup of tea." He talks about the importance of the environmental component of self-directed learning. However, Mrs. Clayton mentions the tools to reach the information, emphasizing the supportive community as well. Mrs. Jacob, too, focuses on the tools to have access to information but adds the importance of mentors:

Mentors. I think mentors are very important. Individualized mentors, a mentor who can see a bit further beyond the student and make suggestions, and open doors, and make connections, you know, being able to connect with other people in the field whether it's by Internet or telephone or some other-meetings.

The participants' definitions of internal and external resources in self-directed learning are compatible with the model of self-directed learning presented in Brockett and Hiemstra (1990). This model recognizes both the differences and similarities between self-directed learning as an instructional method and learner self-direction as a set of personality characteristics. Personal responsibility in their model refers to individuals assuming ownership for their own thoughts and actions.

The way the participants define self-directed learning and the way they talk about the external resources are consistent, which indicates that self-directed learners' beliefs and suggestions are reflected in their decisions and actions. They all mention about the importance of the external resources such as a quiet room, table, internet, books or library, and even further they attach importance to room temperature and their daily schedule. The participants emphasize that these internal and external factors affect their self-directed learning ability.

\section{Suggestions for Parents, Teachers and Communities to Raise Self-Directed Individuals}

The research participants' suggestions to raise self-directed learner-individuals form quite surprisingly a comprehensive summary of what has been stated in scholarly literature except their thoughts on educational goals and objectives. It is noteworthy that although they most probably had not read much, even nothing academic at all, in the field of self-directed learning, and had not even had the opportunity to gather their thoughts on the subject before, they were able to highlight or, at least, mention almost all the major points stated in theoretical and research studies. Their views can be classified as the suggestions for teachers, parents, and the community.

Participants suggest that learning setting should provide more support in terms of tools, and that they should also teach how to use the capacity all the students have to some degree to learn on their own. Mr. Pounder emphasizes the significance of positive language and praising kids, and says that teachers should teach only the foundational things rather than the entire curriculum. In a somewhat similar fashion, Mrs. Jacob suggests a 
training program for teachers, and adds that teachers should be flexible while teaching and should give a chance to their learners so that they can learn how to do something on their own. This is a point made in Fullan (2001) suggesting that teachers should have more time for training for an innovation they would like to implicate. Mrs. Jacob adds, in this respect:

So the teachers have to be trained to see the different needs of the different children and also be trained to find the resources to help the children. And the resources have to be made available. And they also, I think, they have to have the time and the flexibility in the schedule, because if everyone has to learn the same thing there's no room for self-directed learning.

The participants in this study pointed to the importance of the places where learners engage themselves in different activities. Community facilities or resources should help individuals to find out their learning interests.

Mr. Dean says that learning objectives and goals are impeding learning and he adds, "When you think about someone like maybe Einstein I don't think he or- or Edison, I don't think they had the goals when they started. I think they found the goals as they went along, so a sense of- of love of learning is good."

Mrs. Jacob also notes that setting goals could be either good or bad, in rather contrary to Mrs. Clayton. Mrs. Jacob's thoughts about setting goals may be unacceptable in formal education settings. Parents and teachers like setting objectives. However, in her opinion, setting objectives may have a function of not so much different from inhibition. They can only serve as limitations preventing learners from reaching any further. When they are accomplished, there will be no need to do anything more. Therefore, she disfavors the idea of pre-set goals. However, related literature always mentions the importance of the goals.

All the findings from the analysis on the research data are arranged into a model proposed in the following chapter.

\section{CONCLUSION and DISCUSSION}

The results of the study indicate that in order to be a self-directed learner you should have a supportive community to reveal your innate capacity to learn on your own. Research in the area of self-directed learning has primarily focused on finding out the characteristics of self-directed learners by observing them, but less attention has been given to how they define themselves. Although the researchers appreciate the importance of self-directed learning, there are not so many studies done using qualitative research methods to find out the characteristics of self-directed learners. Scholars in this field have focused more on psychological or cognitive dimensions of the self-directed learning (Brockett and Hiemstra, 1991); however, coding data led to the creation of the components of self-directed learning: inner capacity, supportive family, supportive community, and external factors. Moreover, and significantly, this conceptual model, as visualized in figure 1, captures how self-directed learners have developed their strategies to become a self-directed learner. The study begins to unravel the complex process by which participants of the study puts the role of the inner capacity, external environment, supportive family and supportive community. Inner capacity includes self-discipline, motivation, 
curiosity and knowing and evaluating yourself. Families and formal education providers should recognize that being a self-directed learner is a process and it should be assisted since the data via individual interviews has illuminated the internal processes of self-directed learning is significant. Hover, the internal focus is also a limitation because it may fail to capture external influences such as room, table, tools to reach information and even temperature of the room and enough nutrition, and also supportive family and community components of self-direction.

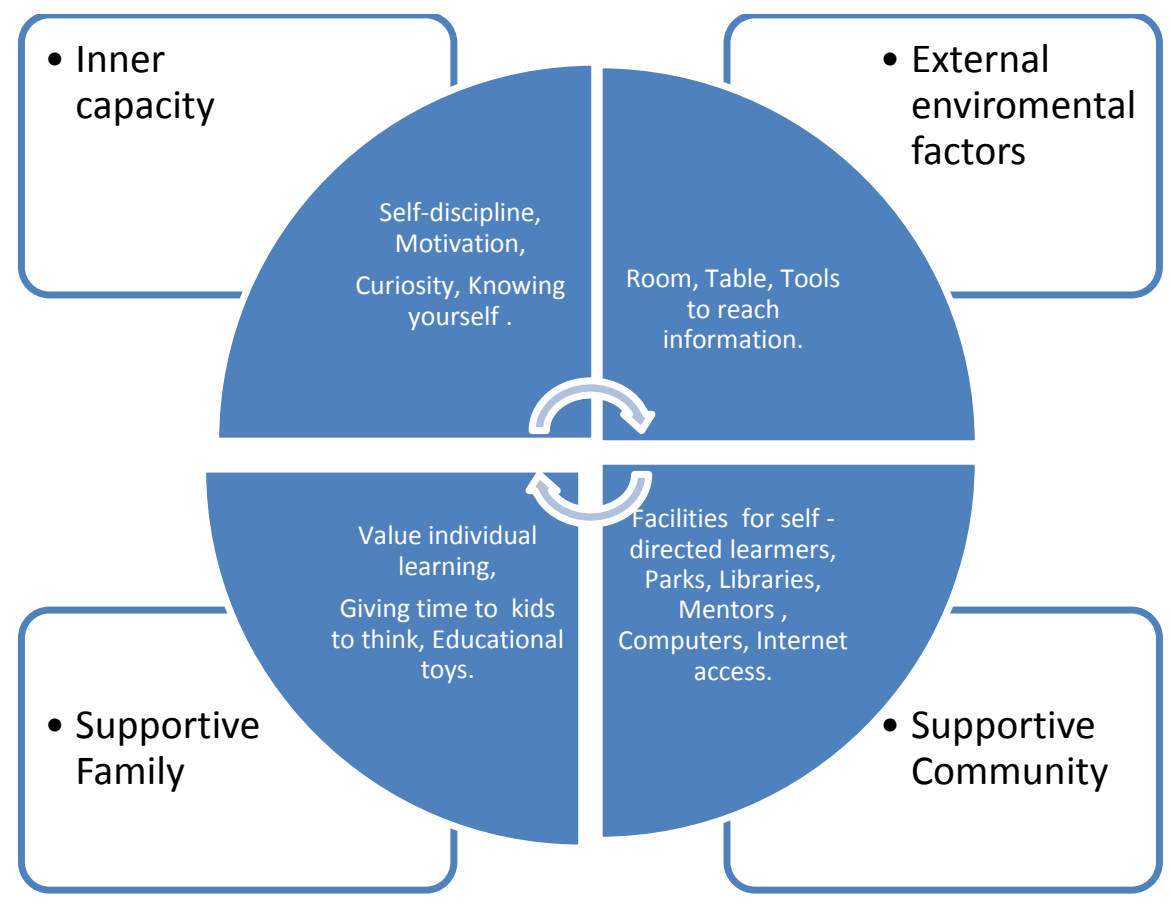

Figure 1: Dimensions that Constitute Self-directed Learning

Self-directed learning has become an essential constituent of personal and professional life because professional life requires people to learn all the way through, adapting new things and adopting new developments for themselves. Learning occurs when learners want to learn what they need to learn, and the whole concept of learning is based on the inner processes. Though implicitly stated, the participants highlight the relationship between the learners' needs, motivation, and self-directedness. If the learners really need to learn something or improve some skills or add to existing knowledge, either for self-actualization or better living conditions, they will have the cine qua non element of motivation, which will provide the impetus for them to keep learning-life-long and self-directed.

Although the participants have no formal education in the field of teaching and learning, they all mention the relatively new terminology in education. Apparently, in some cases, they did not know how to name a concept appropriately and how to address to it specifically; but, they did have an idea of what is going on in their brains. Based on the theory and the beliefs and suggestions of the participants, the researchers came up with a new 
model of self-directed learning. If all the components of self-directed learning are provided for learners, then a smooth transition could be made from lecture based teaching to self-directed learning.

\section{CONCLUSION}

For several decades, scholars in education have strongly stressed the importance of self-directed learning, and they claim that all learners have the capacity to learn for themselves. Due to the time restrictions of formal education, it is difficult for teachers to teach, during the formal education period, what the students need. Therefore, what the formal education settings should provide to learners is some training which enables the learners to learn or reach the information or to develop the skills that they need. While traditional formal education emphasizes memorization of basic rules, which are not internalized because forgotten once testing is complete, self-directed learning emphasizes the intrinsic satisfaction of mastering what learners need to learn. Given our fast-paced, competitive society, people should implement self-directed learning strategies to keep learning outside the schools in a life-long manner.

Based on this study, which explored what self-directed learners are saying, doing or believing to define selfdirected learning, I have found that it has a broader concept than defined by the scholars in the relevant literature. The participants of the study attached importance to inner capacity, social environment and tools to reach the information. Further studies can be done to expand the model and the understanding of self-directed learning. Some further studies can be done with the participants having other characteristics; i.e. with different gender, age, and education level. The assumed difference between females and males, between younger and older age groups, between educated and less-educated would reveal how those diverse groups perceive selfdirected learning in particular and education in general.

\section{ETHICAL TEXT}

"In this article, journal writing rules, publishing principles, research and publishing ethics rules, journal ethics rules are followed. Responsibility belongs to the author for any violations related to the article.

\section{REFERENCES}

Abd-El-Fettah, S. M. (2010). Garrison's model of self-directed learning: Preliminary validation and relationship to academic achievement. The Spanish Journal of Psychology, 13(2), 586-596.

Adelman, C., Kemmis, S. \& Jenkins, D.(1980). Rethinking the case study: Notes from the second Cambridge conference. In H. Simons (Eds.), Towards a science of the singular (pp. need pages). Norwich: CARE.

Bandura, A. (1991). Social cognitive theory of self-regulation. Organizational Behavior and Human Decision Processes, 50, 248-287.

Benson, P. (2007). Autonomy in language teaching and learning. Language Teaching, 40, 21-40. doi:10.1017/ S0261444806003958 
Brockett, R. (1983). Self-directed learning and the hard-to-reach adult. Lifelong Learning: The Adult Years, 6(8), 16-18.

Brockett, R. \& R. Hiemstra (1990), Self-Direction in adult learning: Perspectives on Theory, Research, and Practice, London and New York, Routledge. C.V. Mosby.

Brookfield, S.D. (2013). Powerful techniques for teaching adults. San Francisco: Wiley.

Charmaz, K. (2006). Constructing grounded theory: A practical guide through qualitative analysis. London: Sage Publications Limited.

Charmaz, K. (2014). Constructing Grounded Theory. Thousand Oaks, CA: Sage

Creswell, J. W. (1998). Qualitative inquiry and research design: Choosing among five designs. Thousand Oaks, CA: Sage.

Elias, J. L. \& Merriam, S. (1980). Philosophical foundations of adult education. Malabar, FL: Robert E. Krieger.

Fullan, M. (2001). Leading in a Culture of Change. San Francisco: Jossey-Bass.

Garrison, D. R. (1997). Self-directed learning: Toward a comprehensive model. Adult Education Quarterly, 48(1), 18-33. https://doi.org/10.1177/074171369704800103.

Glaser, B. \& Strauss, A. (1967). The Discovery of Grounded Theory. Chicago: Aldine.

Grow, G. O. (1991) Teaching Learners to b Self-Directed, Adult Education Quarterly, 42, 125-149. https://doi.org/10.1177/0001848191041003001.

Guglielmino, L. M. (1978). Development of the Self-Directed Learning Readiness Scale. Dissertation Abstracts International Section A: Humanities and Social Sciences, 38(11-A), 6467.

Knowles, M.S. (1970), The Modern Practice Of Adult Education: Andragogy Versus Pedagogy, NY: Association Press.

Knowles, M.S. (1975). Self-Directed Learning: A Guide for Learners and Teachers, NY: Association Press.

Knowles, M.S. (1990). The Adult Learner: A Neglected Species, Golf Pub Co.

Leung L. (2015). Validity, reliability, and generalizability in qualitative research. J Family Med Prim Care. 4(3): 324-7

Merriam, S. B. \& Caffarella, R. S. (1999). Learning in Adulthood: A Comprehensive Guide. (2nd Edition). San Francisco: Jossey-Bass.

Miles, M.B. \& Huberman, A.M. (1994). Qualitative Data Analysis, 2nd Ed., p. 10-12. Newbury Park, CA: Sage.

Nunan, D. (1992). Research Methods in Language Learning, Cambridge University Press.

Patton, M. Q. (1990). Qualitative evaluation and research methods (2nd ed.). Sage Publications, Inc.

Yıldırım, A. \& Şimşek, H. (2013). Sosyal bilimlerde nitel araştırma yöntemleri. (Genişletilmiş 9. Baskı). Ankara: Seçkin.

Strauss, A. (1987). Qualitative Analysis. N.Y.: Cambridge University Press

Sze-yeng, F. \& Hussain, R. M. R. (2012). Graduate Entrepreneur Training by Design (GET by Design): An Innovative and Self-Directed Approach to Instructional Design and Development. Procedia - Social and Behavioral Sciences, 46, 3541-3545. https://doi.org/10.1016/j.sbspro.2012.06.101 